\title{
Editorial vol 16, no 2: ICT and the handling of data, information and knowledge
}

\author{
Arthur Tatnall
}

Published online: 18 December 2010

(C) Springer Science+Business Media, LLC 2011

The articles in this issue of the journal cover a wide range of education-related topics relating to the use of ICT in the handling of data, information and knowledge as well as creativity and medium of instruction.

The first article in this issue is by Mark Hellen from the University of London on: Information handling and adaptive expertise and argues the case for investigating the culture of information in primary schools. Hellen notes that recent technological change has altered the relationship between the individual and information, yet this change appears not to be reflected in the culture of schools, especially primary schools. The article investigates that part of the primary ICT curriculum which is categorised as "information handling" to investigate the current likely manifestation of this culture in schools. Using Hatano's concept of Adaptive Expertise as its theoretical perspective, the curriculum is analysed to see how well it is likely to prepare children for a life in which the ability to evaluate information will become a crucial skill needing to be applied in many varied and unforeseeable circumstances.

Next comes an article looking at how: Knowledge articulation dialog increases online university science course outcomes by Kenneth Strang from University of Technology, Sydney, Australia. In Strang's study university postgraduate science courses were investigated to measure how knowledge articulation dialog in discussion forums improved essay and case study scores. In the study, knowledge articulation teaching methodology was integrated from educational psychology and knowledge management literature, while Socratic questioning was drawn from the education community of practice. A quasi-experiment with a strong degree of control was configured with knowledge articulation versus questioning teaching method being the treatment factor.

Laila Mohamed El Fangary from Helwan University, Egypt then outlines the: Mining of Egyptian missions data for shaping new paradigms. This article reviews data mining applications of student databases in Egyptian educational institutions,

\footnotetext{
A. Tatnall $(\bowtie)$

Victoria University, Melbourne, Australia

e-mail: Arthur.Tatnall@vu.edu.au
} 
presenting data mining techniques that predict and improve student retention and success rates. The focus of the paper is to examine how data mining can help in classifying both delayed and successful students to support the implementation of a missioners model. This model may help in supporting decision making regarding the reallocation of Egypt students to other countries.

In the next article: The impact of the medium of instruction: The case of teaching and learning of computer programming, Wilfred Lau and Allan Yuen from The University of Hong Kong note that despite the seemingly good prospects in the Information Technology industry the number of students who are interested in the relevant IT subjects has been limited. They point out that while numerous studies have explored the influence of various variables on programming course participation and performance at a personal level, there have been few studies conducted at a policy level. This article describes a study that examined the impact of the medium of instruction on student learning of computer programming and the effects of gender and prior academic ability on programming performance in Hong Kong.

An article by Giorgos Panselinas and Vassilis Komis from Greece is titled: Using educational software to support collective thinking and test hypotheses in the computer science curriculum. Their study analyses discourse between teacher and student members of three small groups learning in the environment of a stand-alone computer. Two different educational environments are examined: a virtual laboratory and a computer modelling environment. The goal of the research was to exemplify the way these two educational software environments support both the development of collective thinking in peer-peer and teacher-led discussion, and student autonomy. From their results they discuss what they regard as an educationally important structure of software mediation and describe ways that the two software activities acted to resource collective thinking and student initiatives.

The final article in this issue is on: Preservice teachers' perspectives on the definition and assessment of creativity and the role of web design in developing creative potential. It was contributed by Pavlo Antonenko and Ann Thompson from Oklahoma and Iowa State Universities, USA. The article describes an empirical study that explored the perspectives of eight pre-service teachers on the meaning and assessment of creativity and the role of web design in developing creative potential. Data sources included eight semi-structured interviews, web design checklists and interviewer's notes. In the study, five themes emerged from participant responses during data analysis: definition of creativity, assessment of creativity, creativity and instructional strategies, creativity and problem solving and creativity and web design.

While EAIT receives a wide range of articles - as seen in this issue, there are still few that have moved beyond the classroom to discuss topics such as national policies and major projects or lifelong learning in the form of use of computers by retired people, or by people with various disabilities. It is good, however, to see several articles in this issue, including the article on data mining in Egypt, that do this and that tackle other ICT and education-related issues. I would like to see more such articles. 